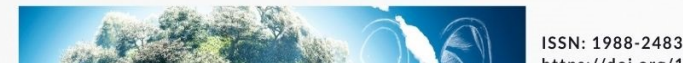

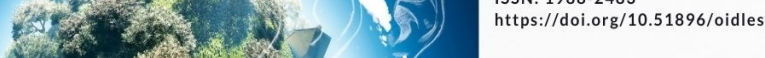 \\ OIDLES. DESARROLLO LOCAL Y ECONOMIA SOCIAL \\ D I c E latindex Econpapers @iDEAs ODialnet ÍnDICEs Sursupira
}

\section{LA DISTRIBUCIÓN SOCIO-TERRITORIAL DE LAS FUENTES DE ABASTECIMIENTO DE AGUA POTABLE EN EL ESTADO Y MUNICIPIO DE TLAXCALA, MÉXICO 2010-2020 *.}

\author{
Sinai Vázquez Jiménez ${ }^{1}$ \\ Alumna de la Maestría en Desarrollo Regional (MDR) en el Colegio de Tlaxcala A.C \\ sinai.vj@coltlax.edu.mx \\ Rafael de Jesús López Zamora² \\ Profesor Investigador adscrito a El Colegio de Tlaxcala A.C
}

lopezza@coltlax.edu.mx

Para citar este artículo puede utilizar el siguiente formato:

Sinai Vázquez Jiménez y Rafael de Jesús López Zamora: "La distribución socio-territorial de las fuentes de abastecimiento de agua potable en el estado y municipio de Tlaxcala, México 2010-2020", Revista OIDLES, Vol 15 № 30 (junio 2021). En línea:

https://www.eumed.net/es/revistas/oidles/vol-15-no-30-junio-2021/fuentes-abastecimiento-agua

\section{RESUMEN}

El crecimiento de la población y de las actividades económicas en los últimos años ha traído problemas socio-territoriales en la distribución, disponibilidad y demanda del agua de uso urbano; por lo que a pesar de considerar la normatividad vigente, los datos de la Comisión Nacional del Agua (CONAGUA), de la Comisión de Agua Potable y Alcantarillado del Municipio de Tlaxcala (CAPAM) y de los comités locales, muestran que aún sigue existiendo un sector de población vulnerable que no cuenta con un servicio eficiente y justo, por ello, el presente tiene como objetivo investigar cómo se da la distribución de la oferta y la disponibilidad del agua potable respecto a la distribución social de la demanda en el territorio del Estado y en particular en el municipio de Tlaxcala. Para ello se destaca la importancia y el papel de la distribución socio-territorial de las fuentes de abastecimiento y almacenamiento de agua potable (pozos profundos y tanques de almacenamiento) en la prestación de los Servicios de Agua Potable, Alcantarillado y Saneamiento (SAPAS), a través de la georreferenciación ligada a la variable población y desde la proximidad, calculada con el Sistema de Información Geográfica (SIG) mediante el programa QGIS, lo que dio como resultado y llevo a la

\footnotetext{
* El presente artículo hace parte de la temática de investigación para la tesis de maestría de la primera autora.

${ }^{1}$ Licenciada en consultoría jurídica por la Facultad de Derecho y Ciencias Sociales de la Benemérita Universidad Autónoma de Puebla (BUAP), alumna de la Maestría en Desarrollo Regional (MDR) en el Colegio de Tlaxcala A.C., San Pablo Apetatitlán, Apetatitlán de Antonio Carvajal, Tlaxcala, México; sinaivj@coltlax.edu.mx

${ }^{2}$ Licenciado y Maestro en Economía, Doctor en Economía Política del Desarrollo por el Centro de Estudios del Desarrollo Económico y Social (CEDES) de la Facultad de Economía de la Benemérita Universidad Autónoma de Puebla (BUAP), Puebla, México. Miembro de la Red de Investigadores Sociales Sobre el Agua, México (RED ISSA). Profesor Investigador adscrito a El Colegio de Tlaxcala A.C., San Pablo Apetatitlán, Apetatitlán de Antonio Carvajal, Tlaxcala, México; lopezza@coltlax.edu.mx.
} 
conclusión final de que la planeación hidráulica urbana debe considerar el aumento y comportamiento de la población como variable clave en la distribución socio-territorial de los SAPAS para lograr coberturas menos desiguales, más justas y más eficientes respecto a la demanda social de aquellos servicios.

Palabras clave: Servicio de agua potable, servicio público, distribución socio-territorial, normatividad y planeación hidráulica.

\section{THE SOCIO-TERRITORIAL DISTRIBUTION OF THE DRINKING WATER SUPPLY SOURCES IN THE STATE AND MUNICIPALITY OF TLAXCALA 2010-2020 *.}

\section{ABSTRACT}

The growth of population and economic activities in recent years has brought about socio-territorial problems in the distribution, availability and demand of water for urban use; Therefore, in spite of taking into account the current regulations, the data of the National Water Commission (CONAGUA), the Drinking Water and Sewerage Commission of the Municipality of Tlaxcala (CAPAM) and the local committees, show that there is still a sector of vulnerable population that does not have an efficient and fair service. The present study aims to investigate how the distribution of drinking water supply and availability compares to the social distribution of demand in the territory of the State and in particular in the municipality of Tlaxcala. For this purpose, the importance and role of the socioterritorial distribution of drinking water supply and storage sources (deep wells and storage tanks) in the provision of Drinking Water, Sewerage and Sanitation Services (SAPAS) is highlighted. This is done through georeferencing linked to the population variable and considering proximity, using a Geographic Information System (GIS) (QGIS software). This analysis resulted and led to the final conclusion that urban hydraulic planning should consider the increase and behavior of the population as a key variable in the socio-territorial distribution of the SAPAS in order to achieve less unequal, fairer and more efficient coverage with respect to the social demand for those services.

Key words: Drinking water service, public service, socio-territorial distribution, water regulation and planning.

\section{INTRODUCCIÓN}

Según Tales de Mileto, el agua "es el elemento principio de las cosas" (Fundación Aqua, 2021) y ante la crisis sanitaria actual aún más, pues de ello dependen la mayoría de las actividades económicas y prioritariamente la salud, es pues un recurso vital para la vida misma y el funcionamiento de cualquier ecosistema; es por ello que los seres humanos utilizan el agua de acuerdo a sus necesidades básicas y durante su aprovechamiento se introducen muchos cambios en el ciclo hidrológico que terminan por afectar, la calidad, distribución, y disponibilidad de la misma.

La Organización de las Naciones Unidas (ONU) considera que para el año 2050 la demanda mundial de agua haya aumentado en un 55\% debido principalmente a demandas relacionadas con la creciente urbanización de los países en desarrollo. Por ello, para tener acceso al recurso, las ciudades tendrán que ir a distancias más lejanas, perforar más profundo para encontrarlo 
- buscar soluciones innovadoras con tecnologías avanzadas de saneamiento para satisfacer las necesidades hídricas de manera sustentable.

Puesto que, según el Programa Conjunto OMSS/UNICEF de Monitoreo del Abastecimiento de Agua y del Saneamiento (2017) informa que 2.3 billones de personas no disponen de instalaciones básicas de saneamiento, como baños o letrinas y al menos 1800 millones de personas en todo el mundo beben agua que no está protegida contra la contaminación de las heces y un número aún mayor bebe agua que se distribuye a través de sistemas vulnerables a la contaminación; existe una distribución desigual, con una gran disparidad entre recursos hídricos y población, por ejemplo: Asia cuenta con el $60 \%$ de la población mundial y sólo el $36 \%$ de este recurso, África tiene un $13 \%$ de la población y sólo dispone del $11 \%$ del agua. Sin embargo, en América del Norte y América Central, en donde reside el $8 \%$ de la población mundial, dispone del $15 \%$ del recurso y América del Sur con únicamente el $6 \%$ de la población disfruta del $26 \%$ de los recursos hídricos (Fernández J. C., 2002), una disparidad notoria se ha venido observando entre población y disponibilidad del agua.

Normativamente en la mayoría de la legislación vigente de los países de la ONU, el agua pertenece a la nación y el agua potable se constituye en un derecho humano básico para todos los ciudadanos. Aunado a esto, si mencionamos que el derecho al agua ha sido objeto de interés para la sociedad civil y para los gobiernos a partir del III Foro Mundial del Agua, en el que se propuso buscar los mecanismos para garantizar este derecho visto desde la visión del servicio público, el Estado es el que debe garantizar su prestación (Comisión Nacional del Agua [CONAGUA], 2012).

Una proyección rápida según la Organización de las Naciones Unidas para la Educación la Ciencia y la Cultura por sus siglas en español y en inglés United Nations Educational, Scientific and Cultural Organization (UNESCO, 2017) se prevé que para el año 2030 el 47\% de la población mundial vivirá ya en zonas con alto estrés hídrico y por ello la mayor parte del crecimiento de la población estará localizada en países en desarrollo, en regiones sin un acceso sostenible al agua potable ni a un saneamiento adecuado.

Actualmente en México el Plan Nacional Hídrico (PNH) 2020-2024 emitido por la Comisión Nacional de Agua (CONAGUA, 2020a). tiene cinco objetivos, siendo uno de ellos el garantizar progresivamente el derecho humano al agua y al saneamiento, especialmente en la población más vulnerable, en donde lo primordial es no dejar sin agua a nadie, pero raramente en el Plan Nacional de Desarrollo (PND) 2019-2024, publicado por la secretaria de Gobernación (SEGOB, 2019) otro programa en particular $u$ otro tipo de objetivo no se menciona a los servicios de agua potable como prioridad.

En el país, el cambio histórico de la proporción entre la población rural y urbana pasó del $57.3 \%$ en 1950 a un $21.0 \%$ en 2014 . Este cambio se explica por el crecimiento de la población urbana, la cual en 2014 era de alrededor de 94.6 millones, el equivalente a casi cuatro quintas partes de la población del país. El proceso de concentración de habitantes en las localidades urbanas ha acelerado su crecimiento, lo que implica fuertes presiones sobre el ambiente por el incremento de la demanda de servicios (luz, drenaje, agua potable, recolección de residuos, entre otros). 
Por ello al año 2015, en los 35 núcleos de población de más de 500 mil habitantes vive el $52.5 \%$ de la población del país; mientras en 2014 , en las cinco zonas metropolitanas más pobladas del país vivían alrededor de 35.4 millones de personas (CONAGUA, 2015).

Así mismo, México se encuentra en el lugar 93 en términos de agua renovable per cápita lo cual es preocupante pues entonces está disminuyendo la cantidad de agua por persona, y de igual forma se intensifican los efectos por el cambio climático, siendo estos cada vez de mayor fuerza (CONAGUA, 2019).

Un problema adicional a la baja disponibilidad del agua en México es su mala distribución, según el uso consuntivo, el 4.1 por ciento del agua concesionada se destina a la industria autoabastecida; el 5.6 a energía eléctrica, excluyendo hidroelectricidad; el 14.6 al abastecimiento público y el 75.7 por ciento a uso agrícola (CONAGUA, 2014, Estadísticas del Agua en México, p. $61)$.

A pesar de que México aún no se encuentra en una situación de vulnerabilidad, en sólo unas cuantas décadas el país pasó de ser un país de alta disponibilidad de agua a uno de baja disponibilidad, debido principalmente al crecimiento demográfico, a la creciente demanda en los distintos usos y al manejo poco eficiente del recurso, situación que ha derivado en una mayor presión sobre los recursos hídricos, en ello tiene mucho que ver el que las empresas trasnacionales, como en el caso de la industria refresquera o automotriz que utilizan este vital líquido para su funcionamiento y que muchas veces no se sabe la veracidad del capital a invertir, ni el pago de los servicios que usan.

En general, a nivel internacional, en México, sus estados y municipios, estudios de caso han presentado un conflicto relacionado con este recurso, en donde existe carencia y necesidad de avanzar en el estudio y sistematización de datos con la idea de comprenderlos mejor y avanzar en el diseño de estrategias de política pública para su prevención y/o resolución.

Otro aspecto muy relacionado es el normativo, pues a pesar de que existe a nivel federal la Ley de Aguas Nacionales (LAN), a nivel estatal, la Ley de Aguas del Estado de Tlaxcala y la Comisión Estatal del Agua de Tlaxcala (CEAT), y a nivel municipal la Comisión de Agua Potable y Alcantarillado del Municipio de Tlaxcala (CAPAM), existe aún población que se encuentra con un servicio intermitente o nulo y desigual, y se ha reconocido que la crisis del agua es una crisis de gestión más que de escasez, por la mala planeación para la distribución y administración ya que la legislación existente es más documental o de escritorio que de aplicación real.

El acuífero al que pertenece el estado de Tlaxcala, es el Alto Atoyac, definido con la clave 2901 en el Sistema de Información Geográfica para el Manejo del Agua Subterránea de la Comisión Nacional del Agua (SIGMAS), se localiza en la porción central del Estado, entre los paralelos 19 $10^{\prime}$ y $19^{\circ} 35^{\prime}$ latitud norte y los meridianos $97^{\circ} 58^{\prime}$ y $98^{\circ} 21^{\prime}$ longitud oeste, cubriendo una superficie de 2,032 km2 (CONAGUA, 2020a).

Geopolíticamente comprende total o parcialmente los siguientes municipios: Tlaxco, Atlangatepec, Tetla de La Solidaridad, Terrenate, Tocatlán, Xaloztoc, Muñoz de Domingo, Arenas, San Lucas Tecopilco, Xaltocan, Hueyotlipan, Españita, Huamantla, Ixtacuixtla de Mariano Matamoros, Santa Ana Nopalucan, Santa Apolonia, Nativitas, Tetlatlahuca, San Jerónimo Zacualpan, 
San Damián Texoloc, Santa Catarina Ayometla, Santa Cruz Quilehtla, San Lorenzo Axocomanitla, Tepeyanco, San Juan Huactzingo, Santa Isabel Xiloxoxtla, Xicohtzinco, San Pablo del Monte, Tenancingo, Mazatecochco de José María M., Acuamanala de Miguel Hidalgo, Teolocholco, San Francisco Tetlanohcan, La Magdalena Tlaltelulco, Tlaxcala, Panotla, Papalotla de Xicohténcatl, Totolac, Amaxac de Guerrero, Sta. Cruz Tlaxcala, Yauhquemecan, Apizaco, Coaxomulco, Tzompantepec, San José Teacalco, y Zacatelco (CONAGUA, 2020b).

De acuerdo con la información del censo de aprovechamientos de la Comisión Nacional del Agua realizado en 2011, se registraron 890 aprovechamientos de agua subterránea, de los cuales 734 corresponden a pozos, 102 a norias y 54 manantiales; del total de pozos 600 se encuentran activos y 134 inactivos; 79 norias activas y 23 inactivas; finalmente, los manantiales 54 se consideran activos (CONAGUA, 2020b).

En el Estado de Tlaxcala según datos del Censo Económico del Instituto Nacional de Estadística y Geografía (INEGI, 2019) el volumen total de agua suministrada fue de 36,845 miles de metros cúbicos, de los cuales 28,974 fueron de uso doméstico, 3,390 de uso comercial, 711, de uso industrial, 2,397 de servicios públicos y 1,373 distribuida por medio de pipas, lo que en porcentaje corresponde a más del $80 \%$ el uso doméstico.

Por ello, de manera más específica, en el Plan Estatal de Desarrollo (PED) 2017-2021 del Gobierno del Estado de Tlaxcala (GET,2017) se menciona que Tlaxcala es uno de los estados con mayor densidad poblacional del país, ocupa el puesto 28 por el número de habitantes, sin embargo, tiene una densidad poblacional de 329 habitantes por $\mathrm{km}^{2}$, la cuarta mayor del país y cinco veces mayor que el promedio nacional 63 habitantes por $\mathrm{km}^{2}$. De manera continua el Consejo Nacional de Población (CONAPO, 2017) señala que la población del estado aumentará a 1,363,576 habitantes para el año 2020 y a 1,516,712 para el año 2030, con una tasa de crecimiento de 1.21 y 0.92 por cada 100,000 habitantes respectivamente.

En la aplicabilidad y en cuanto a la estructuración de las entidades encargadas de la gestión del agua de uso urbano (organismos operadores), se aprecia una tendencia incipiente a asegurarles capacidad profesional y financiera e independencia, no obstante prevalece el crecimiento desordenado, concentrado y fragmentado en la gestión y prestación de los servicios, así como el uso ineficiente y por lo tanto ha aumentado la presión y la sobreexplotación sobre los acuíferos, lo que ha propiciado al mismo tiempo un creciente proceso de degradación ecológica y contaminación de las aguas superficiales de la cuenca. Debido a lo anterior, se hace necesaria la investigación interdisciplinaria sobre el tema y gestión de estos servicios y su impacto sobre la población beneficiaria.

Por ello se analizó e investigo la problemática actual desde la gestión de los Servicios de Agua Potable, Alcantarillado y Saneamiento (SAPAS), ya que su gestión y distribución socioterritorial en el municipio y sus localidades, es fundamental para garantizar a la mayoría de la población su acceso digno y justo, pero también la protección, recuperación y conservación de las fuentes de abastecimiento y la infraestructura hidráulica tanto en el Estado, como en el municipio de Tlaxcala. 
Por lo anterior, se parte de la siguiente pregunta de investigación: ¿Como se da la distribución, la disponibilidad y oferta de agua potable respecto a la distribución social de la demanda, en el territorio del Estado y municipio de Tlaxcala? Lo que conduce a proponer como objetivo general del presente, investigar la distribución de la disponibilidad y oferta de agua potable respecto a la distribución social de la demanda, para mostrar la importancia de la distribución socioterritorial de las fuentes de abastecimiento y almacenamiento de agua potable (pozos profundos y tanques de almacenamiento), a través de la georreferenciación de las fuentes y los tanques de almacenamiento en el Estado y en el municipio de Tlaxcala.

La hipótesis propuesta es que la distribución de la disponibilidad y oferta de agua potable, a través de las fuentes y tanques de almacenamiento en el territorio del Estado y municipio de Tlaxcala, está estrechamente ligada a la distribución socio-territorial de la demanda, puesto que sin ellos sería imposible proporcionar y operar los servicios de agua potable, alcantarillado y saneamiento a la población urbana del estado y municipio de Tlaxcala.

De acuerdo con los resultados se han encontrado una falta de planeación hidráulica adecuada, así como la deficiente capacidad técnica y financiera de los prestadores de servicios (Organismos Operadores o CAPAM's), lo que ha redundado en coberturas desiguales en el Estado y el Municipio de Tlaxcala, en donde la mayoría de veces no se cuenta con el mapeo y planeación del servicio garantizados, así como la prestación del servicio en municipios en donde no corresponde el domicilio, además del pago de contribuciones, por lo que existe una fuga de ingresos; además de que número de pozos y tanques de almacenamiento de agua no corresponden con el tamaño de la población o el número de tomas domiciliarias existente, entre otros problemas.

Para el logro de sus objetivos el articulo está dispuesto y se presenta bajo el formato de Introducción, Métodos, Resultados y Discusión (IMRyD). Comprende, una introducción; materiales y métodos empleados; presentación y discusión de resultados de investigación; conclusiones y recomendaciones y referencias bibliográficas.

\section{MATERIALES Y MÉTODOS EMPLEADOS}

Marx define del concepto condiciones generales de la producción (CGP), el cual se refiere "al proceso colectivo de reproducción de la fuerza de trabajo y a las unidades de consumo colectivo (aglomeraciones) en las que dicho proceso se realiza" (Castells, 2001: 9; citado por López, 2014: 74), en sí esas condiciones de reproducción social y material se refieren a todos los satisfactores necesarios, no solo para vivir, sino también para garantizar la reproducción y perpetuación de los trabajadores y determinan el valor de la fuerza de trabajo que está formado por un elemento físico y otro histórico o social, ya que no solo se trata de la vida física, sino de la satisfacción de ciertas necesidades que brotan de las condiciones sociales en que viven y se educan los hombres (Marx, 1974; citado por López, 2014).

Jean Lojkine (1979:162; citado por López, 2014) señala que “... la intervención estatal es la forma más elaborada y perfeccionada de la respuesta capitalista a la necesidad de socializar las fuerzas productivas", lo hace a través de sus políticas urbanas para regular los efectos de la segregación y mutilación del equipamiento urbano, en esa intervención mediante el financiamiento 
público de los medios de consumo colectivo ha permitido al capital poner en juego el desarrollo de las condiciones generales de la producción. Para este autor los medios de consumo colectivo pertenecen a las condiciones generales directas de la producción y no añaden valor al creado en el proceso productivo, se distinguen por que su valor de uso es colectivo, ya que se dirige a una necesidad social que sólo puede satisfacerse colectivamente, por la duración de su consumo, porque son de lenta rotación de capital y rentabilidad capitalista muy escasa y por ser valores de uso complejos, duraderos, inmóviles y no poseer valores de uso que se tornen en productos materiales separados, exteriores a las actividades que los produjeron (Lojkine, 1979).

O'Connor (1991) clasifica estas mismas condiciones generales de la producción en condiciones físicas externas (en términos de viabilidad de los ecosistemas); fuerza laboral (en términos de bienestar físico y mental de los obreros) y condiciones comunales (en términos de "capital social"): infraestructura, etcétera. En los tres conceptos están implicados el espacio y el "entorno social", espacio urbano y otras formas de espacio estructurados por la relación entre personas y ambiente y fundamentales en el desarrollo de las sociedades.

Y Castells (2001), por su parte señala que los servicios públicos y de equipamiento son bienes de consumo social de carácter público, tradicionalmente proporcionados por el Estado, como son los servicios de agua potable y los denomina a su vez "medios de consumo objetivamente socializados", mismos que por razones históricas dependen en cuanto a su producción, distribución y gestión, de la intervención del Estado, pero que son colectivos por naturaleza e indispensables para la misma existencia. Por su parte Shiva (2007) hace énfasis en que el agua es un bien comunal porque constituye la base ecológica de toda la vida y porque su preservación y distribución equitativa dependen de la cooperación entre miembros de la comunidad.

Mas recientemente, Garza (2013) desarrolla aquel concepto de condiciones generales de la producción (CGP), e identifica, además de las ya existentes para la reproducción de los trabajadores, a las utilizadas por el aparato productivo como parte esencial del concepto de ciudad como fuerza productiva, es pues una categoría incluyente a diferencia de la idea acuñada por Marx y más que una parte infraestructural externa a las empresas se refieren al capital fijo de un servicio complejo, por ello para el las CGP son:

Un elemento de un servicio (electricidad, dotación de agua, comunicaciones, etc.) que requiere para prestarse de instalaciones adicionales de tipo administrativo, además de equipo de transportes $y$, lo que es igualmente indispensable, de empleados, trabajadores, cuadros técnicos especializados, ....niveles gerenciales que planean y dirigen....a la empresa. (Garza, 2013: p. 120)

Por lo que Garza distingue en las CGP una categoría dual, un binomio orgánicamente articulado que constituye una unidad indivisible (CGP-SGP) en la que están representados, por un lado, los renglones infraestructurales, esto es, las condiciones generales de la producción (CGP); y por el otro, la gestión o servicios generales de la producción (SGP). Este binomio de condiciones y servicios generales de la producción está conformado por medios de producción naturales y construidos (infraestructura), así como por trabajadores e insumos. Todo se requiere para realizar el proceso 
general de producción y reproducción de la fuerza de trabajo. El binomio-es externo a las empresas individuales, pero indispensable para realizar sus operaciones (Garza, 2013).

De acuerdo con lo anterior el binomio CGP-SGP está integrado por componentes naturales, construidos y de gestión pública. Los componentes naturales y construidos presentan relación directa con la explotación de los recursos naturales, en este caso la explotación del agua a través de las obras e infraestructura hidráulicas que captan y la almacenan para canalizarla y abastecer a las ciudades para su utilización en las actividades productivas y por la población; se refieren a los pozos profundos y tanques de almacenamiento, que juegan un papel sumamente importarte, pues de no contar con ellos, el servicio no podría llegar a los domicilios, de tal manera que su creación, mantenimiento y uso continuo son parte fundamental de las condiciones generales de la producción, por ende de los bienes de consumo colectivos, además de resaltar su importancia para la educación, salud, cultura y esparcimiento; generación de pagos de derechos y aprovechamientos y hasta para fines electorales.

El componente de la gestión pública se refiere a que toda clase de infraestructura requiere de factores geográficos como la topografía y el clima en donde se incorporan cuestiones de detonación y planeación del desarrollo por parte del estado, así como de políticas de explotación y preservación y gestión en beneficio o perjuicio de toda la población (Garza, 2013).

Así entendida esta categoría, el binomio CGP-SGP conformado por las condiciones generales de la producción (CGP) y los servicios generales de la producción (SGP) es la que ha guiado la investigación, le da fundamento teórico, permite explicar el problema de investigación, lograr el objetivo planteado y demostrar la hipótesis propuesta. Es importante destacar que dicho referente teórico permite relacionar y hacer congruente el objetivo con los métodos y técnicas de investigación utilizados, así como con la obtención de los resultados de la investigación, como parte de la gestión de los servicios de agua potable y saneamiento (SAPAS) y el papel que juega el Estado, ya sea como proveedor o como regulador de los bienes y servicios públicos, que finalmente son "medios de consumo colectivo".

Los materiales utilizados corresponden a Información pública disponible en materia de agua para el estado y municipio de Tlaxcala, tomando como años de análisis 2010 y 2020, (libros, capítulos de libros, revistas, informes, etc.) considerando los datos de los Censos de Población y Vivienda del Instituto Nacional de Estadística y Geografía (INEGI) 2010 y 2020 en donde se obtuvieron las cifras pertinentes a las variables de la distribución de la Población Estatal y municipal (INEGI, 2010, 2020).

Así mismo, a través del Sistema para la Consulta de Información Censal 2016 de la página del Instituto Nacional de Estadística y Geografía (INEGI), en el apartado de Descarga Masiva se obtuvieron los datos para hacer el análisis de la distribución territorial de la infraestructura hidráulica, los pozos profundos ${ }^{3}$ y tanques de almacenamiento ${ }^{4}$ de agua en el Estado y municipio de Tlaxcala, para obtener así la información más reciente (INEGI, 2020b).

${ }^{3}$ Se entiende como pozo profundo aquel que se caracteriza por tener una profundidad mayor a 30 metros y a través del cual se extrae el agua de fuentes subterráneas, cerca de la superficie del suelo o de capas geológicas profundas, para su potabilización y diferentes usos.

${ }^{4} Y$ tanque de agua al depósito cerrado utilizado para almacenar el agua que se extrae de dichos pozos para proseguir con su distribución hacia las redes de abastecimiento. 
Para el acopio, codificación y análisis de la información de la base de datos se procedió de la siguiente manera: Con apoyo del Sistema de Información Geográfica (SIG), mediante el programa QGIS versión. 2.18, se cargó la capa vectorial correspondiente a servicios "p"; con el fin de lograr un marco homogéneo, compatible y comparable se utilizó el Marco de Referencia Oficial para los Estados Unidos Mexicanos, siendo este el International Terrestrial Reference Frame 1992, con datos de época 1998.0 (ITRF92), con Id de autoridad en este software 6362. Posteriormente se realizó la extracción del objeto seleccionado, en este caso "pozo" y "tanque de agua", calculando las distancias de este a los alrededores, con una clasificación de valores de acuerdo a la escala del mapa y se agregó el estado y el municipio según fuera el caso, para así observar las zonas con mayor y menor cobertura y poder estudiar la distribución socio-territorial de los mismos.

\section{PRESENTACIÓN Y DISCUSIÓN DE RESULTADOS DE INVESTIGACIÓN}

En este apartado se ilustra y evalúa el servicio en lo general (Estado de Tlaxcala) y en lo particular (Municipio de Tlaxcala) para corroborar el hecho de que en la zona o región donde se establece mayor población se localizan pozos y tanques de agua para suministrar el servicio, o en caso contrario, donde existe menos, de igual forma, en donde, la falta de uno de estos dos deja el área desprotegida sin abasto contrarrestándolo con datos del Instituto Nacional de Estadística y Geografía (INEGI), así como información estadística de la Comisión Nacional del Agua (CONAGUA).

Antes de comenzar, es importante precisar que el sistema para proveer del servicio de agua potable comprende de manera general desde la extracción, conducción, almacenamiento, distribución y posterior saneamiento, para poder llegar a los hogares de cientos de miles de familias a nivel nacional de unas 1,169,936 personas en el estado de Tlaxcala y a nivel municipal 89,795 personas según datos de INEGI en el Censo de Población y Vivienda (2010); para el año 2020 la población municipal se actualizo a 99,896 personas y de 1,342,977 a nivel Estatal, según datos del INEGI en el Censo de Población y Vivienda (2020).

Estimaciones del Consejo Nacional de Población (CONAPO) a 2017, entre 2012 y 2030 la población del país se incrementará en 20.4 millones de personas y para el año 2030, aproximadamente 75 por ciento de la población estará ubicada ya en localidades urbanas.

Con la información obtenida del Instituto Nacional de Estadística y Geografía, en la Tabla 1 se puede observar que hubo un aumento de población estatal entre el año 2010 y el 2020 de 173, 041 personas y de 10,101 personas a nivel municipal, por lo que es una cifra considerable, aproximadamente 14 porciento a nivel estatal y 11 porciento a nivel municipal, lo que representa el 1 por ciento aproximadamente promedio anual, lo cual indica en automático un aumento considerable de la demanda del servicio en términos absolutos y de demanda per cápita para los usos básicos.

\section{Tabla 1}

\section{Comparativo poblacional en el Estado y Municipio de Tlaxcala}
Territorio
Año 2010
Año 2020
Aumento (\%) 


\begin{tabular}{lccc} 
Estatal & $1,169,936$ & $1,342,977$ & 14.79 \\
Municipal & 89,795 & 99,896 & 11.24 \\
\hline
\end{tabular}

Fuente: Elaboración propia con datos del INEGI

A nivel estatal y en un periodo más amplio, en la Tabla 2 la variación de la población de 2005 a 2020 incremento con un total de 274,770 habitantes lo que corresponde a $25.72 \%$ respecto al 2005 , teniendo un promedio de crecimiento de $1.71 \%$ anual y 18,318 habitantes, las cuales necesitaran abastecerse del servicio de agua potable de manera continua anualmente.

Tabla 2

\begin{tabular}{lcccc}
\hline \multicolumn{5}{l}{ Evolución de la población en el Estado de Tlaxcala $2005-\mathbf{2 0 2 0}$} \\
\hline Indicador & $\mathbf{2 0 0 5}$ & $\mathbf{2 0 1 0}$ & $\mathbf{2 0 1 5}$ & $\mathbf{2 0 2 0}$ \\
Habitantes & $1,068,207$ & $1,169,936$ & $1,272,847$ & $1,342,977$ \\
\hline
\end{tabular}

Fuente: Elaboración propia con datos de INEGI

De manera más específica referente al servicio de agua potable y alcantarillado en la Tabla 3 se puede visualizar de 2007 a 2018 existió un aumento de $1.4 \%$ de población que cuenta con el servicio de agua potable en 11 años, representando un promedio de .1\% anual; en el caso del servicio de alcantarillado aumento $4.7 \%$ siendo este un $0.4 \%$ anual, dato mayor que el servicio de agua potable, lo cual nos deja para reflexionar si es más importante tener servicio de agua potable o de alcantarillado en la población a nivel estatal.

Tabla 3

Población con servicio de agua potable y alcantarillado en el Estado de Tlaxcala

\begin{tabular}{lllll}
\hline Indicador & $\mathbf{2 0 0 7}$ & $\mathbf{2 0 1 3}$ & $\mathbf{2 0 1 5}$ & $\mathbf{2 0 1 8}$ \\
Agua potable & 97.40 & 97.20 & 97.90 & 98.80 \\
Alcantarillado & 90.80 & 94.90 & 95.50 & 95.50 \\
\hline
\end{tabular}

Fuente: Elaboración propia con datos de INEGI

De igual manera en la Tabla 4, se puede observar el precio mayor fue en 2007, pasando a 2013 con una reducción de 1 peso, y subiendo 30 centavos para 2015, siendo este el dato más actualizado se tiene al momento a nivel estatal.

Tabla 4

Precio del metro cúbico de agua y su variación en el Estado de Tlaxcala

\begin{tabular}{lcccc}
\hline Indicador & $\mathbf{2 0 0 7}$ & $\mathbf{2 0 1 3}$ & $\mathbf{2 0 1 5}$ & $\mathbf{2 0 1 8}$ \\
$\begin{array}{l}\text { Precio (pesos por } \\
\text { m3) }\end{array}$ & 6.30 & 5.30 & 5.60 & ND \\
$\begin{array}{l}\text { Variación anual } \\
\text { (Por ciento) }\end{array}$ & 7.10 & 3.90 & 2.20 & ND \\
\hline
\end{tabular}

Fuente: Elaboración propia con datos de INEGI 
Refiriéndonos a la subcuenca Alto Balsas Zahuapan-Atoyac y/o Acuífero Atoyac-Zahuapan es la única región hidrológica en el estado de Tlaxcala donde para el 2010 se practicaron todos los usos del agua registrados, para lo cual se utilizó $64.5 \%$ de los $227.18 \mathrm{hm} 3$ aprovechados en el estado, dividido en los siguientes rubros: Población (43.73\%), Agricultura de riego (44.07\%), Industrial (11.09\%) Servicios (0.79\%), Pecuario (0.18\%) Acuícola (0.18\%) (CONAGUA, 2014, p. 61) y para 2017 pasaron a $271.3 \mathrm{hm} 3$, lo que quiere decir que se extrajeron $44.12 \mathrm{hm} 3$ más, pero al verificar su uso en Población se utilizó (33.5\%), en Agricultura de riego (60\%), Industrial (6.4\%) cambiando drásticamente el panorama y reduciendo significativamente en un $10 \%$ el agua para la población. (CONAGUA, 2018, p. 82)

En el caso de la fuente de abastecimiento, en la Tabla 5 se puede observar que del año 2005 a 2016, en 11 años se concesionaron 5 pozos más, aproximadamente 2 pozos por año y 1 manantial lo que nos hace visualizar la gravedad del problema, para obtener mayor cantidad de agua para abastecer a mayor cantidad de población.

\section{Tabla 5}

Fuentes de abastecimiento y volumen de extracción concesionado en el Municipio de Tlaxcala

\begin{tabular}{|c|c|c|c|c|}
\hline \multirow[t]{2}{*}{ Indicador } & & 2005 & 2010 & 2016 \\
\hline & Total & 23 & 26 & 28 \\
\hline \multirow{2}{*}{$\begin{array}{l}\text { Fuentes de } \\
\text { abastecimiento }\end{array}$} & $\begin{array}{l}\text { Pozo } \\
\text { profundo }\end{array}$ & 22 & 24 & 26 \\
\hline & Manantial & 1 & 2 & 2 \\
\hline \multirow{3}{*}{$\begin{array}{l}\text { Volumen de extracción } \\
\text { concesionado (miles } \\
\text { de metros cúbicos) }\end{array}$} & Total & 12,187 & 12,268 & 12,348 \\
\hline & $\begin{array}{l}\text { Pozo } \\
\text { profundo }\end{array}$ & 11,555 & 11,555 & 11,635 \\
\hline & Manantial & 632 & 712 & 712 \\
\hline
\end{tabular}

Fuente: Elaboración propia con datos de INEGI

Cabe resaltar que del Censo de Población y Vivienda del Instituto Nacional de Estadística y Geografía (INEGI) se tomó la información sobre la dimensión, estructura y distribución espacial de la población, así como de sus principales características socioeconómicas y culturales (CONAPO, 2020, pp. 143).

Sobrino et al. (citado por CONAPO, 2020, pp. 174), hace énfasis en que la manera en que se distribuye territorialmente la población plantea nuevos retos, puesto que en el marco del desarrollo sustentable se trata de inducir cambios orientados a los elementos que contribuyen al bienestar de la población, en este sentido entrarían primordialmente los servicios de agua potable y saneamiento así como todo su ciclo para llegar a los hogares-y que además desde un enfoque integral reconozcan las interacciones población, ambiente y factores mediadores.

Por ello, cobran gran importancia en esta investigación las tendencias que están y van a modificar el crecimiento poblacional de las ciudades a través del tiempo. Es así que, a nivel estatal, en la Figura 1, en el año 2010 se puede observar que, de los 60 municipios con los que cuenta el Estado de Tlaxcala, solo 5 de ellos concentran la mayor cantidad de población, siendo estos 
Tlaxcala, Chiautempan, San Pablo del Monte, Apizaco y Huamantla, y que representan el $8.33 \%$ de los municipios del Estado, con una población media alta, se encuentran 6 municipios, siguiendo de una población media de 10 municipios, media baja 16 y baja 23 de ellos.

\section{Figura 1}

\section{Concentración de población por municipio del Estado de Tlaxcala en 2010}

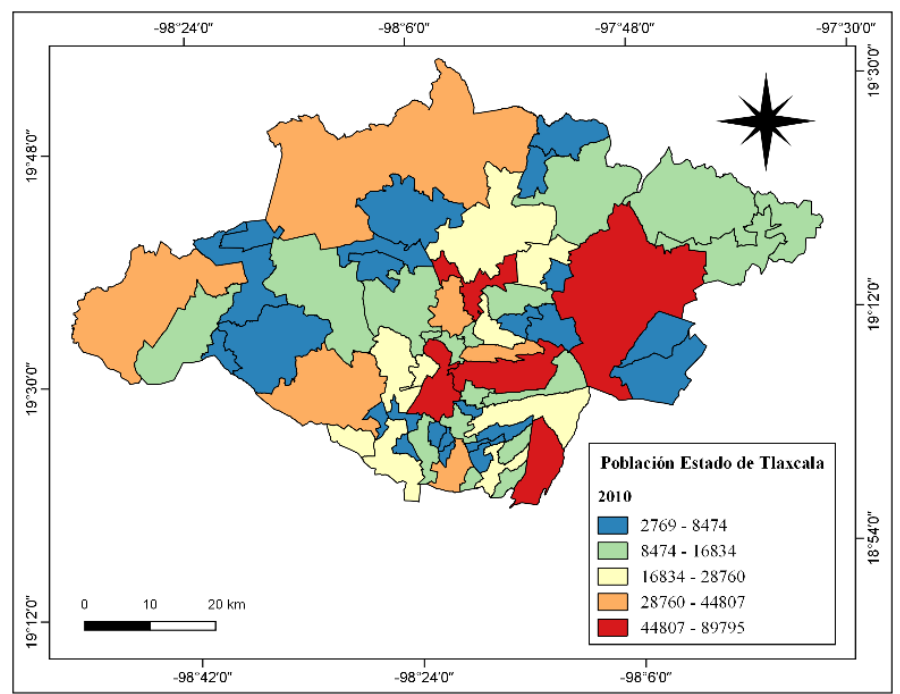

Fuente: Elaboración propia con datos de (INEGI 2010).

Al año 2020, en la Figura 2 se puede observar que, con información más actual, se ha reducido a 2 municipios los que concentran la mayor cantidad de población siendo estos, Tlaxcala y Huamantla, de los 4 que eran a 2010, de Tlaxcala. Con una población media alta 3, siendo estos Apizaco, Chiautempan y San Pablo del Monte, con una población media 8 de ellos, y media baja 18 y baja población 29 .

\section{Figura 2}

Concentración de población por municipio del Estado de Tlaxcala en 2020

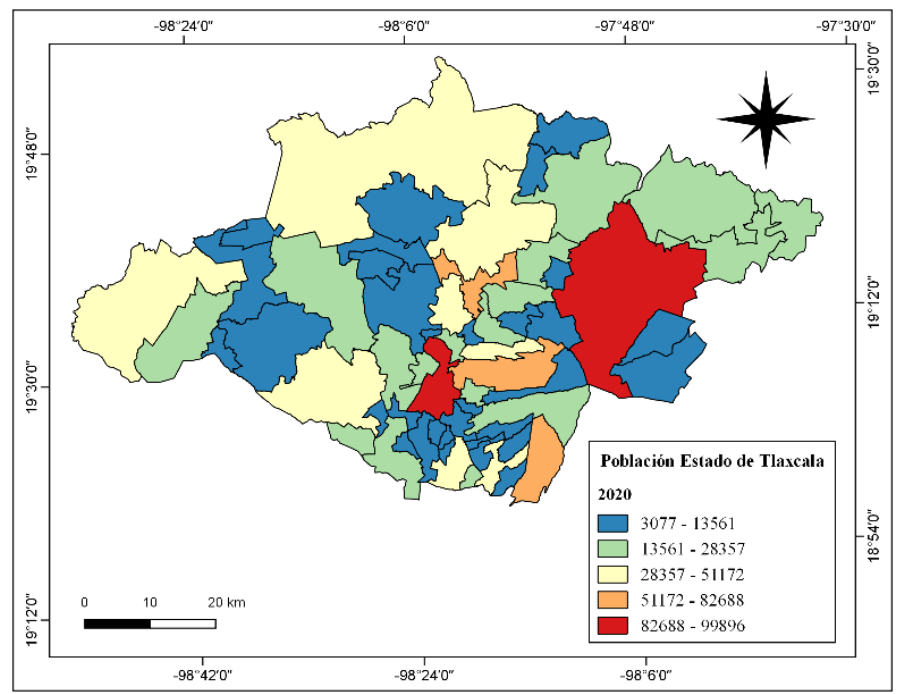

Fuente: Elaboración propia con datos de (INEGI 2020a). 
En la Figura 3 se puede observar que la concentración de los Pozos en el Estado se da en la Región Centro Sur, ya que es donde se realizan mayores obras hidráulicas (en este caso pozos profundos) para poder surtir la demanda de servicios derivada de la alta concentración de población y de factores productivos. Aunado a ello, se observan zonas vulnerables en donde no existen pozos y por consiguiente no se extrae agua, como son los municipios de Españita en la Región Oeste, casi en su totalidad y algunas partes de San Pablo del Monte, Teolocholco, San Francisco Tetlanohcan, Zitlaltépec, Ixtenco, Huamantla, en la Región Sur y en la Región Norte en Tlaxco, Terrenate, Lázaro Cárdenas y Emiliano Zapata.

\section{Figura 3}

\section{Zonas con proximidad de Pozo de Agua Potable en el Estado de Tlaxcala 2019}

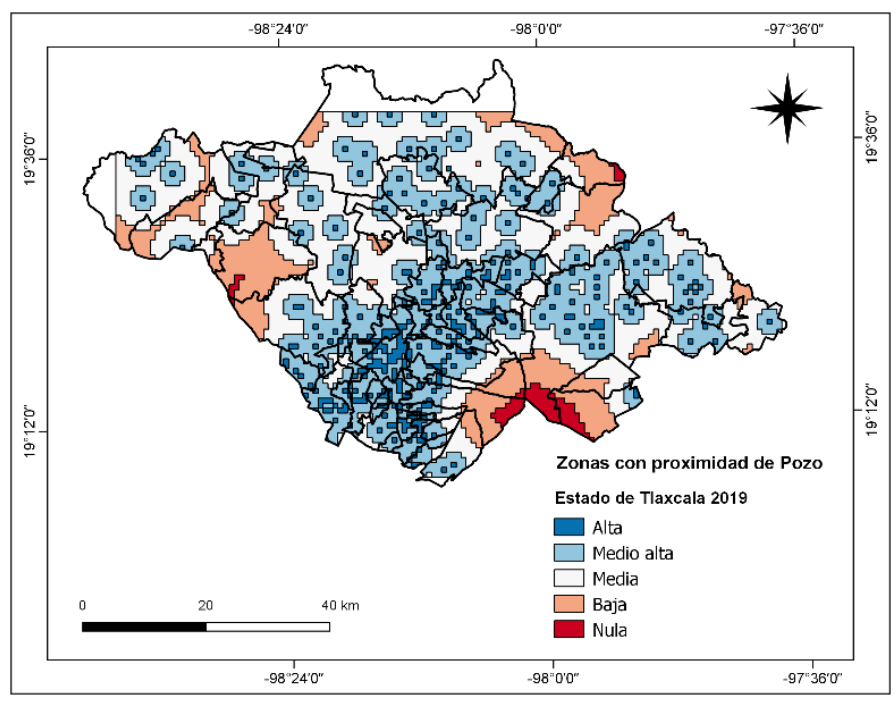

Fuente: Elaboración propia con datos de (INEGI, 2019).

En el caso de los tanques de almacenamiento, en la Figura 4 se observa que existe un mayor número de tanques de agua que pozos, lo cual obedece al esquema y diseño de distribución de la infraestructura necesaria para llegar a cada hogar, mediante las redes de distribución y de manera más eficiente, económica y con menos permisos que un pozo, inclusive de mayor apoyo político-administrativo o programas sociales estatales, como es el caso del Programa de Agua Potable, Drenaje y Saneamiento (PROAGUA).

Y se puede observar que existe de manera más homogénea en la mayoría de las regiones la existencia de un tanque de agua, sin embargo, en la Región Centro Sur existe una mayor concentración en comparación con todas las demás regiones. Al igual que con la variable pozos, podríamos decir que se debe a la visualización de la población, puesto que en la misma Región Centro sur es donde existe una mayor concentración poblacional en comparación con la Región Norte, Este y Oeste. 
Finalmente, quedan menos áreas desprotegidas en comparación con las variables pozo, pero de igual forma se observan en las mismas áreas, siendo estas Teolocholco, San Francisco Tetlanohcan, Zitlaltépec, Huamantla, así como algunas partes finales de Tlaxco y Calpulalpan.

\section{Figura 4}

\section{Zonas con proximidad de Tanque de Agua en el Estado de Tlaxcala 2020}

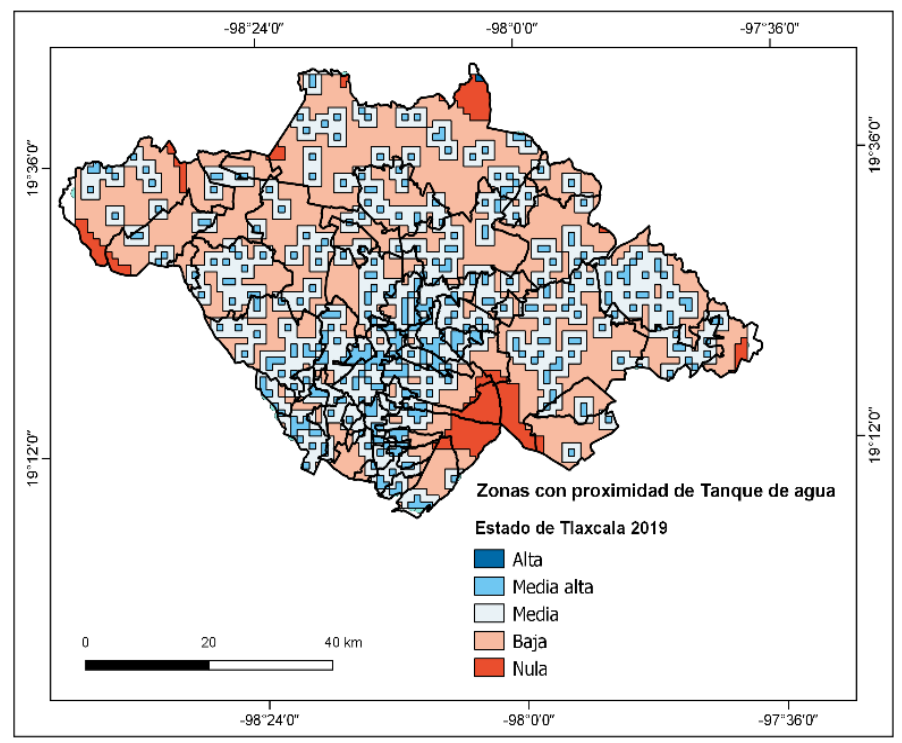

Fuente: Elaboración propia con datos de (INEGI, 2019).

En el caso del Municipio de Tlaxcala, en la Figura No. 5 y 6, se observa la concentración de población en las localidades del Municipio de Tlaxcala y sus cambios significativos a través de 10 años, por ejemplo, en 2010 la localidad con más población es Ocotlán y continuo así a 2020, seguida de la capital Tlaxcala de Xicohtencatl a 2010, en donde a 2010 cambia y se convierte Santa María Acuitlapilco, en el segundo lugar, un dato interesante al pensar comúnmente que la capital siempre concentraría la mayor población.

Posteriormente en el año 2010, tenemos a la localidad de Acuitlapilco catalogada como de población media, con una población media baja 2 localidades y con población muy baja 7 de las 13 localidades. En comparación en 2020, se tiene al municipio de Tlaxcala, con población media baja, se mantiene con las mismas 2, y con población muy baja de igual manera. Lo que quiere decir que, aunque ha aumentado la población en términos absolutos, por su distribución territorial en el Municipio de Tlaxcala, se concentra principalmente en Ocotlán, Acuitlapilco y Tlaxcala, identificados pues, como los polos de desarrollo y crecimiento demográfico donde se concentran las dependencias de gobierno, empresas privadas y comercio del Municipio. 


\section{Figura 5}

Concentración de población por localidad del municipio de Tlaxcala 2010.

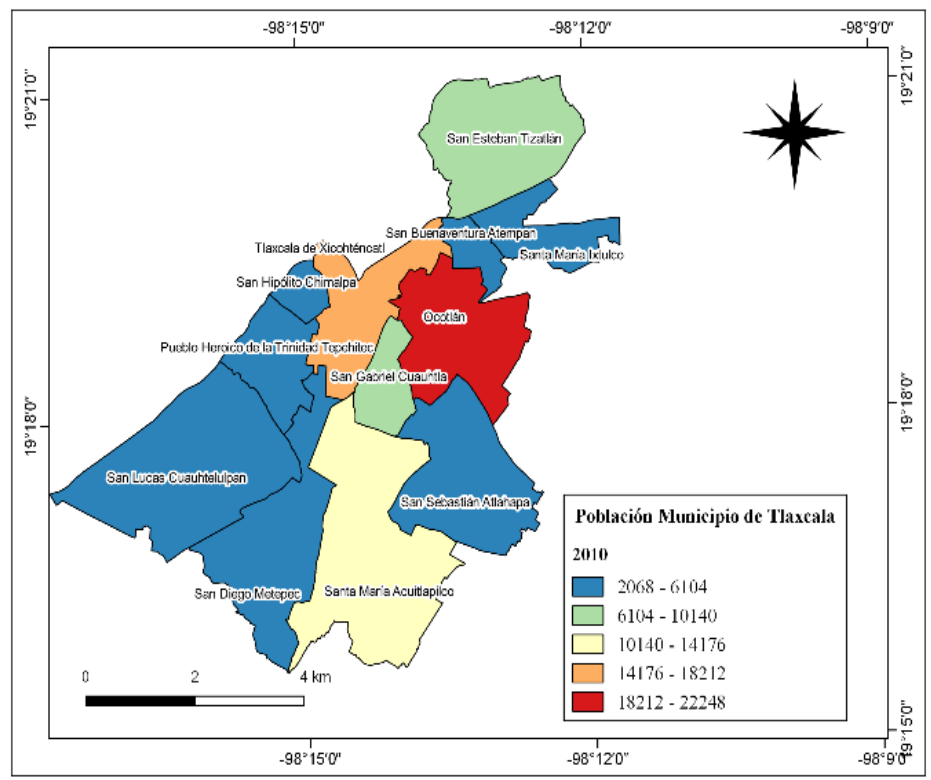

Fuente: Elaboración propia con datos de (INEGI ,2010).

\section{Figura 6}

Concentración de población por localidad del municipio de Tlaxcala 2020.

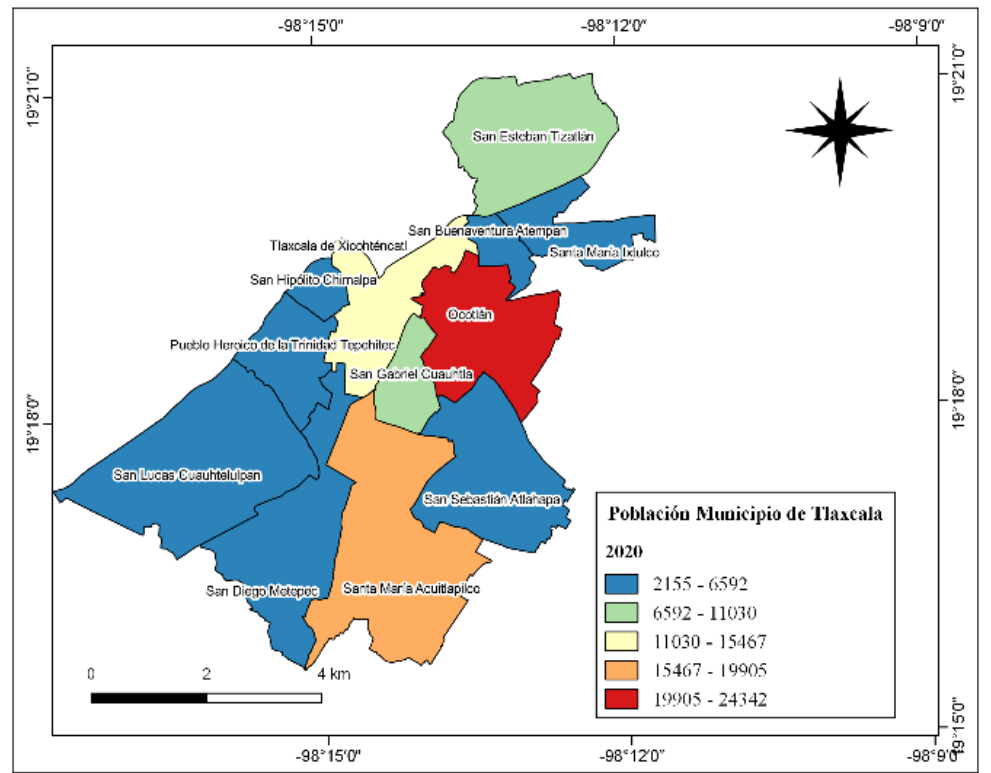

Fuente: Elaboración propia con datos de (INEGI, 2020a).

En el Plan Municipal de Desarrollo Tlaxcala 2017-2021, se señala: "Sobre los servicios municipales en las viviendas, para el 2010 el 87\% disponían de agua entubada dentro de la vivienda, mientras que la cobertura de drenaje estaba cubierta con el $98.3 \%$, el servicio sanitario en un $98.8 \%$ y la cobertura de electricidad en un 99.4\%" esto según lo emitido por el Ayuntamiento del Municipio de Tlaxcala (Ayuntamiento del Municipio de Tlaxcala [AMT, 2017]).

Así mismo en su diagnóstico de comunidades resalta que, en Ocotlán, San Esteban Tizatlán y San Lucas Cuauhtelulpan, el segundo principal problema es el agua, en cambio en San 
Gabriel Cuahutla, San Sebastián Atlahapa, San Hipólito Chimalpa y Pueblo Heroico de la Trinidad Tepehitec, el problema del agua se ubica en el tercer lugar (AMT, 2017).

Con esto se puede observar que al menos 7 de 11 de las comunidades del municipio de Tlaxcala tienen entre sus problemas principales el suministro de agua potable (Ayuntamiento del Municipio de Tlaxcala, 2017), esto debido al nivel de disponibilidad, pues en las últimas décadas se ha observado un acelerado proceso de deterioro y sobreexplotación; las fuentes de aprovechamiento, tanto superficial como subterránea, han venido presentando un deterioro constante, que ha derivado en una baja o escasa disponibilidad del recurso, en gran parte como consecuencia de la presión ejercida por las actividades económico-industriales de las ciudades (CONAGUA, 2015) trayendo como consecuencia enfermedades de distintos tipos (estomacales, insuficiencia renal, anemia, leucemia, etc.), por ello según la Organización Mundial de la Salud (OMS) el agua de mala calidad puede aumentar el riesgo de enfermedades diarreicas, en particular, el cólera, la fiebre tifoidea, la salmonelosis, otras enfermedades víricas gastrointestinales y la disentería (2017).

En la Figura 7, podemos observar cómo en ciertos puntos los pozos no llegan a abastecer todas las áreas y algunas quedan desprotegidas a nivel municipal, como es el caso de algunas zonas de las localidades de San Diego Metepec, Acuitlapilco, Tlaxcala y Santa María Ixtulco, y con ello se puede observar existe una distribución territorial inadecuada porque si bien es cierto, es sabido que muchas veces al existir colindancia con otros municipios y localidades estos se abastecen de los mismos aunque jurídicamente y administrativamente no les corresponde. Municipal.

\section{Figura 7}

\section{Zonas con proximidad de Pozo de Agua Potable en el Municipio de Tlaxcala 2019}

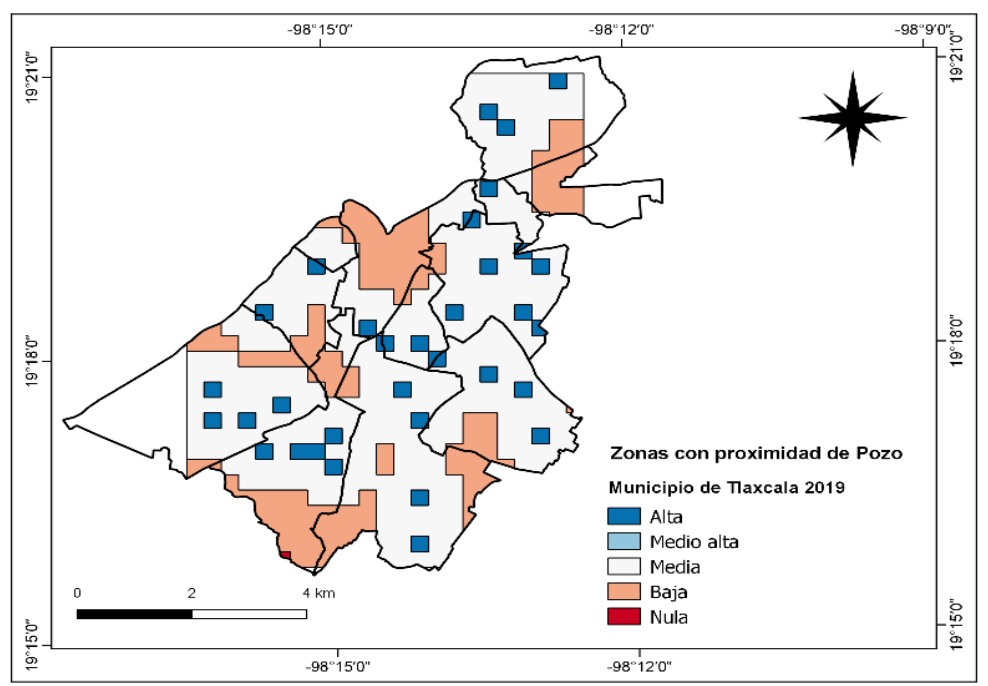

Fuente: Elaboración propia a partir de datos del INEGI 2019.

En el caso de los tanques de agua a nivel localidad, con la Figura 8 se puede demostrar la poca existencia de estos. Y nuevamente podemos ver la concentración de estos en el centro del municipio, principalmente en Tlaxcala, Ocotlán, San Gabriel Cuauhtla, y Acuitlapilco, dejando desprotegidas todas las orillas, que coincide de manera clara, con la concentración de la población en estos 4 municipios en donde se ubica la población mayor y medio alta. Esto nos demuestra que sí 
hay tanques disponibles en la zona, pero otra cuestión crucial es, si los Servicios de Agua Potable, Alcantarillado y Saneamiento (SAPAS) dan un servicio eficiente y adecuado a la población.

\section{Figura 8}

\section{Zonas con proximidad de Tanque de Agua en el Municipio de Tlaxcala 2019}

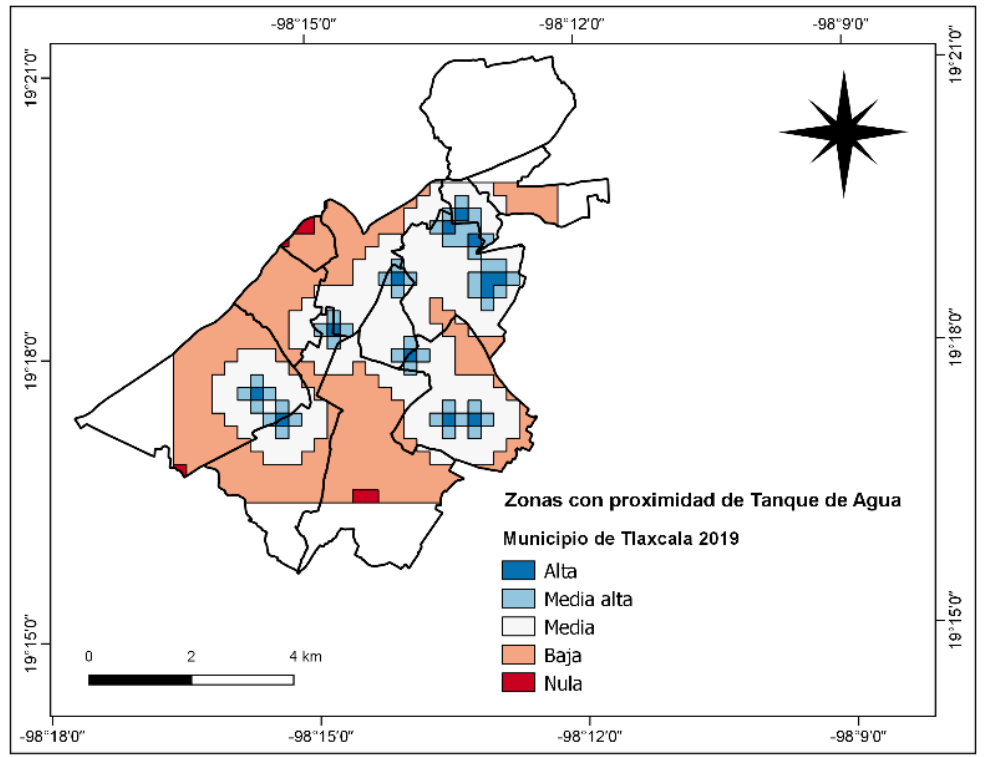

Fuente: Elaboración propia a partir de datos del INEGI 2019.

\section{Tabla 6}

Principales indicadores de la Comisión de Agua Potable y Alcantarillado del Municipio de Tlaxcala (CAPAM)

\begin{tabular}{lcccc}
\hline \multicolumn{1}{c}{ Indicador } & $\mathbf{2 0 1 0}$ & $\mathbf{2 0 1 5}$ & $\mathbf{2 0 2 0}$ & Aumento \\
$\begin{array}{l}\text { Número de } \\
\text { habitantes }\end{array}$ & 89,795 & 95,091 & 99,896 & 10,101 \\
$\begin{array}{l}\text { Extracción media } \\
\text { diaria }\end{array}$ & $\mathrm{ND}$ & $\begin{array}{c}18,157.95 \mathrm{m3} \\
\text { diarios }\end{array}$ & $\begin{array}{c}19,680.22 \mathrm{m3} \\
\text { diarios }\end{array}$ & $\begin{array}{c}1,522.27 \mathrm{m3} \\
\text { diarios }\end{array}$ \\
$\begin{array}{l}\text { Extracción media } \\
\text { mensual }\end{array}$ & $\mathrm{ND}$ & $\begin{array}{c}552,304.5 \mathrm{~m} 3 \\
\text { mensual }\end{array}$ & $\begin{array}{c}598,475.49 \mathrm{~m} 3 \\
\text { mensual }\end{array}$ & $\begin{array}{c}46,170.99 \mathrm{~m} 3 \\
\text { mensual }\end{array}$ \\
$\begin{array}{l}\text { Extracción anual de } \\
\text { agua }\end{array}$ & $\mathrm{ND}$ & $\begin{array}{c}6,627,654 \mathrm{m3} \\
\text { anual }\end{array}$ & $\begin{array}{c}7,183,283 \mathrm{~m} 3 \\
\text { anual }\end{array}$ & $\begin{array}{c}555,629 \mathrm{~m} 3 \\
\text { anual }\end{array}$ \\
$\begin{array}{l}\text { Horas en operación } \\
\text { Número de tomas }\end{array}$ & 12 horas & 18 horas & 22 horas & 10 horas \\
Pozos & $\mathrm{ND}$ & 13,958 & 15,519 & 1561 \\
\hline
\end{tabular}

Fuente: Elaboración propia con datos del INEGI y CAPAM (2020b).

Para finalizar con este apartado en la Tabla 6 se puede observar de manera clara el aumento que se ha tenido en el municipio de Tlaxcala, en número de habitantes en 10 años, en donde un promedio aproximado anual en extracción media diaria seria de 152,227 m3, en el caso de extracción mensual 4,617 m3, y 5,562.9 m3 anuales, 1 hora más de operación cada año y 156 tomas, además de 1.6 redondeando a 2 pozos nuevos por año. 
Esto ha generado conflictos y disputas entre usuarios, presidentes de comunidad y municipio, así como con el Estado, pues aún predomina la visión utilitaria capitalista respecto al agua y sus servicios, según la cual el agua es una mercancía y muy lucrativa, con intenciones de privatizarla, solución que se da a la deficiente gestión y administración pública, a la "escasez", uso y reutilización, excavar más profundo, o tener más horas de servicio para poder cubrir la demanda social y abastecer del servicio a la población, solo con soluciones desde la oferta, sin embargo esta no es una solución veras y eficiente al problema, es un problema que se tiene que atacar desde el fondo, estudiando a profundidad la gestión, planeación y operación actual del servicio; el tiempo de vida del material de la distribución del servicio; el aumento de la población; la ubicación geográfica; topografía; tarifas; valoración del recurso; los diferentes usos que se le dan, así como el proceso de reintegrarla al medio ambiente mediante los procedimientos de saneamiento y tratamiento de las aguas residuales, entre otros. De acuerdo con la información y los resultados de investigación arriba verificamos que el acceso al servicio de agua potable, visto desde las condiciones infraestructurales de la extracción, esto es de los pozos profundos y su distribución por medio de los tanques de almacenamiento de agua, es condición necesaria de la oferta de los servicios y es una variable asociada estrecha y directamente relacionada con el tamaño y crecimiento de la población, así como de las actividades económicas de las ciudades, particularmente del municipio y el estado de Tlaxcala.

\section{CONCLUSIONES Y RECOMENDACIONES}

En el Estado de Tlaxcala y Municipio de Tlaxcala, la distribución geográfica del agua potable, esto es de la infraestructura hidráulica representada por las fuentes y los tanques de almacenamiento para su distribución no coincide con la distribución geográfica de la población, esto es que no hay convergencia entre oferta y demanda de estos servicios y que existen diferencias considerables entre la Región Centro Sur que concentra ambos, con la Región Norte, Este u Oeste, con un total de 152 pozos y 207 tanques de agua (AMT, 2011).

La información refleja una situación crítica al hacer el análisis. Por ejemplo en el Municipio de Tlaxcala para el año 2011 se contaba con 52 pozos profundos, los cuales son la única fuente de abastecimiento de agua limpia con más de 14.8 millones de metros cúbicos concesionados para todos los usos, dos millones más de lo registrado en el 2003, tres manantiales que se utilizan para agua de uso doméstico; de este total, 9 pozos son de uso público urbano de localidades mayores a 2,500 habitantes con un volumen concesionado de 8,521,109 de metros cúbicos, 14 pozos son de uso público urbano de localidades menores a 2,500 habitantes con un volumen concesionado de agua de 3, 034,239 metros cúbicos, 12 pozos para uso de servicios con un volumen concesionado de 179,960 metros cúbicos, 6 pozos de uso industrial con un volumen concesionado de agua de 447,832 metros cúbicos de agua y 12 pozos de uso agrícola con un volumen concesionado de casi 2.7 millones de metros cúbicos de agua (AMT, 2011).

Esta información hasta la fecha no ha cambiado mucho puesto que la Comisión de Agua Potable y Alcantarillado del Municipio de Tlaxcala maneja 11 pozos, y cada comunidad 1 o 2 dando un aproximado de 16, un aumento en 10 años de 4 pozos únicamente, de acuerdo con información 
recabada con informantes clave del operador. Por ello, se pueden llegar a observar áreas aun faltantes de un pozo o un tanque cercano y por consiguiente el agua escasea, además que estos asentamientos humanos o infraestructuras, pueden ocasionar que sea imposible quizá ya la instalación de un tanque regulador. Además, que de por si la distribución actual no puede ser de todo heterogéneo, debido fundamentalmente a las diferencias en la distribución de las precipitaciones, cuentas y subcuencas, y hace que no todas las regiones tengan la misma disponibilidad de acuerdo a su oferta y demanda.

Por lo anterior y de acuerdo con la hipótesis propuesta, se demostró que la distribución de la disponibilidad y oferta de agua potable, a través de las fuentes y tanques de almacenamiento en el territorio del estado y municipio de Tlaxcala, está estrechamente ligada a la distribución socioterritorial de la demanda, ya que sin ellos sería imposible proporcionar y operar los servicios de agua potable, alcantarillado y saneamiento a la población urbana del Estado y municipio de Tlaxcala.

Los resultados muestran la falta de una planeación hidráulica adecuada, una deficiente capacidad técnica y financiera de los prestadores de servicios (Organismos Operadores o CAPAM's), lo que ha redundado en coberturas desiguales en el estado y el Municipio de Tlaxcala, en donde la mayoría de veces no se cuenta con el mapeo y planeación del servicio garantizados, así como la prestación del servicio en municipios en donde no corresponden domicilios, o el pago de contribuciones, por lo que existe una fuga de ingresos; además de que el número de pozos y tanques de almacenamiento de agua no corresponden con el tamaño de la población o el número de tomas domiciliarias existente, entre otros problemas.

Todo esto tiene que estar totalmente integrado a un ejercicio de planeación de la distribución hídrica en las ciudades, acompañado de medidas orientadas (desde la demanda) para reubicar volúmenes de agua de los diferentes sectores habitacionales, comerciales e industriales, estableciendo prioridades de acuerdo a un programa de re sectorización de distritos y circuitos de distribución de las zonas urbanizadas, contemplando el crecimiento de los hogares, comercios y empresas, en la ciudad; con el antecedente de una real planeación hidráulica estatal que tome en cuenta los tres principales usos del agua: urbano, agrícola e industrial.

Por lo tanto, para evaluar como tal el recurso resulta imprescindible analizar las características de esta población en particular, sus aspectos socio-económicos, los bienes y servicios que predominan en la estructura económica de la región y sus dimensiones social y cultural, entre otros.

Puesto que a pesar de que el Estado es el encargado de abastecer este servicio, como lo menciona Garza en el binomio de las CGP-SGP, ello implica a muchas otras variables y subvariables económico-financieras, sociales y ambientales que deben tenerse en cuenta en la planeación, gestión y operación de la infraestructura para hacer más eficientes y sustentables los servicios de agua y saneamiento, para que lleguen a toda la población urbana, considerando los componentes naturales, construidos y de gestión pública.

En este sentido el agua es un bien natural renovable, pero a ritmos muy lentos, pero la sociedad o el Estado en general, de acuerdo a lo establecido y por su naturaleza infraestructural debe construir la red hidráulica y operarla para llevarla a todos los hogares y domicilios el servicio, 
mediante acciones de gestión y control, particularmente en lo que corresponde a la infraestructura necesaria, es el caso de los pozos y tanques de agua, donde influyen factores geográficos, como la topografía y el clima; pero más aún, en México tiene que gestionarlo para su uso eficiente y adecuado, situación normada y hasta su aplicabilidad, desde los organismos internaciones, como la ONU, FAO, u otras, nacionales como las leyes y Normas Oficiales Mexicanas (NOM) a nivel estatal mediante planes y programas, hasta el nivel municipal.

Por todo esto, según la UNESCO los factores demográficos y un aumento del consumo como consecuencia de una mayor renta per cápita, agregaríamos el desarrollo industrial y urbano de los últimos años, son las principales causas de la presión ejercida sobre los recursos hídricos y del estrés hídrico registrado en los indicadores al respecto. Es un hecho que aún se registra un fuerte crecimiento de la población, de acuerdo con los datos, la población mundial está creciendo a un ritmo de 80 millones de habitantes por año, lo que implica un incremento de la demanda de agua dulce de aproximadamente 64 mil millones de metros cúbicos anuales (2017).

Para poder frenar esto, es necesario actuar desde la demanda, más que desde la oferta, lo que implica una mejor gestión y operación en la prestación del servicio por parte de los organismos operadores en las ciudades, lo que va desde la mejora en la gestión de los sistemas e infraestructura de distribución de agua en las ciudades, de los sistemas de riego en el campo y en la industria, fomentar y divulgar nuevas prácticas para el uso y reusó de agua residual, fomentar la recolección, tratamiento y uso de agua pluvial para incrementar la oferta sin necesidad de continuar depredando y sobreexplotando el acuifero.

Ya que conforme lo observado en la población aún se tiene la creencia de que el agua es ilimitada y nunca se acabará, idea errónea, el problema se debe atacar desde la demanda, desde los usuarios, principalmente desde la familia, crear conciencia social, la educación y conservación de este recurso, en donde la solución no es extraer más agua o cavar más profundo el pozo, sino cambiar los hábitos actuales de consumo y de vida y orientarlos hacía hábitos y conciencia social sustentable. En donde la prioridad sea obtener y extraer solo los recursos necesarios, realizar nuestras actividades cotidianas de manera eficiente, conservando y cuidando el medio ambiente, ya que con el modelo socio económico actual y el consumismo que lo caracteriza, a mayores niveles de vida corresponden mayores porcentajes de consumo de agua requerida por habitante, mayores tazas de extracción como lo muestran las evidencias estadísticas, según las cuales, la extracción de agua se han triplicado en los últimos 50 años (UNESCO, s.f.).

Otro tema es la contaminación de las aguas superficiales y el grave riesgo de contaminación que corren los acuífero en México, ello también reduce significativamente el agua dulce disponible para consumo humano; aquello, debido a todos los desechos arrojados a las aguas, metales pesados, colorantes, residuos industriales y químicos, vertimientos humanos como el aceite comestible, desechos agrícolas, entre muchos más; sumado a todo lo antes mencionado, y a las variaciones espaciales y temporales del comportamiento del ciclo hidrológico, determina que la cantidad existente disponible para todos los usos haya empezado a disminuir, lo que puede conducir hacía una crisis hídrica. 
Todo esto hace que las poblaciones pobres y marginales siempre sean las más afectadas, sumándole el cambio climático natural, además del causante antropogénico, que produce diferentes efectos sobre los recursos hídricos, observados cada vez mayores inundaciones, sequias, ciclones, frentes fríos, reducción de los caudales que obviamente empeoran la calidad del agua, por lo que el objeto de estudio relacionado con los SAPAS debe ser una preocupación multi, trans e inter disciplinario de eminente urgencia en el país y en el mundo, a nivel estatal, regional, municipal y local.

Por todo lo anterior se recomienda generar mayor conciencia social, se necesita planificar aún más la gestión y distribución de los servicios de agua potable y el saneamiento por parte de las autoridades hídricas nacionales y locales pero derivado todo de un "nuevo plan", acorde a la realidad social y económica actual, para lograr coberturas máximas y llegar a toda la población, en cantidades y calidad adecuada a la norma, pero además, para qué la gestión de aquellos bienes de consumo colectivo y condiciones generales de producción sean aprovechados, con la intención de lograr un verdadero desarrollo local sustentable de nuestras localidades y ciudades. No es suficiente que la norma este plasmada en los documentos, sino que debe aplicarse en la realidad, por lo que se hace necesario y urgente arribar a modelos de gestión social y participativos, dirigidos a las poblaciones de manera más justa y equitativa y así actuar sobre los desequilibrios económicos, sociales y territoriales.

\section{REFERENCIAS BIBLIOGRÁFICAS}

Ayuntamiento del Municipio de Tlaxcala (AMT) (2011) Plan Municipal del Desarrollo 2011-2013.

Ayuntamiento del Municipio de Tlaxcala (AMT) (2017) "Plan Municipal de Desarrollo 2017-2021" Disponible en: http://www.capitaltlaxcala.gob.mx/wp-content/uploads/2018/07/Plan-Municipalde-Desarrollo-Tlaxcala-Revisado-para-presentacion-ante-cabildo.compressed-1.pdf Acceso en: junio 2020

Castells, M. (2001) Problemas de investigación en sociología urbana. 16를 Ed. México: Siglo Veintiuno Editores.

Comisión Nacional del Agua (CONAGUA) (2012) El Reto Hídrico en México Obtenido de VI Foro Mundial del Agua en Marsella: http://www.conagua.gob.mx/CONAGUA07/Contenido/Documentos/FINAL_ESP.pdf Acceso en: febrero 2020

Comisión Nacional del Agua (CONAGUA) (2014) Estadísticas del Agua en México Edición 2014 México, Secretaría de Medio Ambiente y Recursos Naturales.

Comisión Nacional del Agua (CONAGUA) (2015) Atlas del Agua en México, México, Secretaría de Medio Ambiente y Recursos Naturales.

Comisión Nacional del Agua (CONAGUA) (2018) Estadísticas del Agua en México Edición 2018 México, Secretaría de Medio Ambiente y Recursos Naturales.

Comisión Nacional del Agua (CONAGUA) (2019) Capitulo 8. Agua en el Mundo Disponible en: https://www.gob.mx/conagua/acciones-y-programas/agua-en-el- 
mundo\#: :text=De\%20los\%20200\%20pa\%C3\%ADses\%20de,de\%20agua\%20renovable\%20 per\%20c\%C3\%A1pita Acceso en: julio 2020.

Comisión Nacional del Agua (CONAGUA) (2020a) Plan Nacional Hídrico 2020 - 2024 Disponible en: https://www.gob.mx/conagua/documentos/programa-nacional-hidrico-pnh-2020-2024, Acceso en: enero 2020

Comisión Nacional del Agua, (CONAGUA) (2020b) "Actualización de la Disponibilidad Media Anual de Agua en el Acuífero Alto Atoyac (2901), Estado de Tlaxcala" Subdirección General Técnica Gerencia De Aguas Subterráneas

Consejo Nacional de Población (CONAPO) (2017) Proyecciones de la población de México y las entidades federativas 2016-2050 - Tlaxcala" Disponible en: https://www.gob.mx/cms/uploads/attachment/file/487369/29_TLA.pdf Acceso en: julio 2020.

Consejo Nacional de Población (CONAPO) (2020) "La situación demográfica de México" Año 2, núm. 2, 2020, secretaria de Gobernación, Ciudad de México.

Fernández J. C. (2002) El agua como fuente de conflictos. Repaso de los focos de conflictos en el mundo. UNESCO.

Fundación Aquae (2021) Tales de Mileto: El agua es el principio de todas las cosas, Madrid, España disponible en: https://www.fundacionaquae.org/el-agua-principio-de-todas-las-cosas-queexisten-tales-demileto/\#: :text=Todo\%20es\%20agua\%2C\%20es\%20el\%20principio\%20de\%20todas\%20las \%20cosas\&text=Para\%20el\%20fil\%C3\%B3sofo\%20Tales\%20de,fuente\%2C\%20principio\%2 Ou\%20origen, Acceso en: diciembre 2019

Garza G. (2013) Teoría de las Condiciones y los Servicios Generales de la Producción. Centro de Estudios Demográficos, Urbanos y Ambientales, El Colegio de México, A. C., México, D. F. Gobierno del Estado de Tlaxcala (GET) (2017) Plan Estatal de Desarrollo (PED) 2017- 2021 Disponible en: https:/prensa.tlaxcala.gob.mx/2017/Junio/PED\%2020172021/PED\%2017\%2021\%20HD.pdf Acceso en: enero 2020

Instituto Nacional de Estadística y Geografía (INEGI) (2010) Censo de Población y Vivienda del 2010, Disponible en: https://www.inegi.org.mx/app/descarga/default.html Acceso en: enero 2020 Instituto Nacional de Estadística y Geografía (INEGI) (2019) Censo Económico 2019, Disponible en: https://www.inegi.org.mx/programas/ce/2019/ Acceso en: enero 2020

Instituto Nacional de Estadística y Geografía (INEGI) (2020a) Censo de Población y Vivienda del 2020, Disponible en: https://www.inegi.org.mx/app/descarga/default.html Acceso en: enero 2020

Instituto Nacional de Estadística y Geografía (INEGI) (2020b) Descarga Masiva Disponible en: https://www.inegi.org.mx/app/descarga/default.html Acceso en: enero 2020

Lojkine, Jean (1979) El marxismo, el estado y la cuestión urbana. México: Siglo XXI.

López, Zamora, R. (2014) Los servicios de agua potable y saneamiento en la ciudad de Puebla. Sujetos sociales, poder y modelo de gestión 1984-2010. Benemérita Universidad Autónoma de Puebla (BUAP), Puebla, México. 
López, Zamora, R. y Ramos Montalvo (2015). Expansión urbana, agua potable y saneamiento en la zona metropolitana Puebla Tlaxcala (ZMPT). Revista Observatorio Iberoamericano del Desarrollo Local y la Economía Social (OIDLES), Año 9, No. 18 En línea: http://www.eumed.net/rev/oidles/19/saneamiento.html Acceso en: diciembre 2019

O'Connor, J. (1991) Las condiciones de producción. Por un marxismo ecológico, una introducción teórica. Revista Ecología política No. 1, septiembre.

OMSS/UNICEF (2017) Progresos en Materia de Agua Potable, saneamiento e higiene, Informe de actualización de 2017 y línea de base de los ODS. Disponible en: https://data.unicef.org/wpcontent/uploads/2018/01/JMP-2017-report-es_0.pdf Acceso en: diciembre 2019

Organización de las Naciones Unidas (ONU) (2015) La Asamblea General adopta la Agenda 2030 para el Desarrollo Sostenible, Disponible en: https://www.un.org/sustainabledevelopment/es/2015/09/la-asamblea-general-adopta-laagenda-2030-para-el-desarrollo-sostenible/\#: :text=View\%20Larger\%20Image,La\%20Asamblea\%20General\%20adopta\%20la\%20Agenda\%202030\%20para\%20el\%20Des arrollo,el\%20acceso\%20a\%20la\%20justicia Acceso en: diciembre 2019

Organización de las Naciones Unidas para la Educación la Ciencia y la Cultura (UNESCO) (2017) Programa Mundial de Evaluación de los Recursos Hídrico (WWAP) disponible en: http://www.unesco.org/new/es/natural-sciences/environment/water/wwap/facts-andfigures/all-facts-wwdr3/fact1-demographics-consumption/ Acceso en: diciembre 2019 Organización de las Naciones Unidas para la Educación la Ciencia y la Cultura (UNESCO) (2017) Programa Mundial de Evaluación de los Recursos Hídricos (WWAP) disponible en: http://www.unesco.org/new/es/natural-sciences/environment/water/wwap/facts-andfigures/all-facts-wwdr3/fact1-demographics-consumption/ Acceso en: diciembre 2019 Secretaria de Gobernación (SEGOB) (2019) "Plan Nacional de Desarrollo 2019-2024" Ciudad de México, Disponible en: https://www.dof.gob.mx/nota_detalle.php?codigo=5565599\&fecha=12/07/2019 Acceso en: marzo 2020

Shiva, V. (2007) Las guerras del agua. Privatización, contaminación y lucro. México: Siglo XXI.

Sistema Nacional de Información del Agua (SINA) (2020) Glosario, disponible en: http://sina.conagua.gob.mx/sina/ Acceso en: mayo 2020 